\title{
Atomic Force Microscopy Measurement of Heterogeneity in Bacterial Surface Hydrophobicity (Supporting information)
}
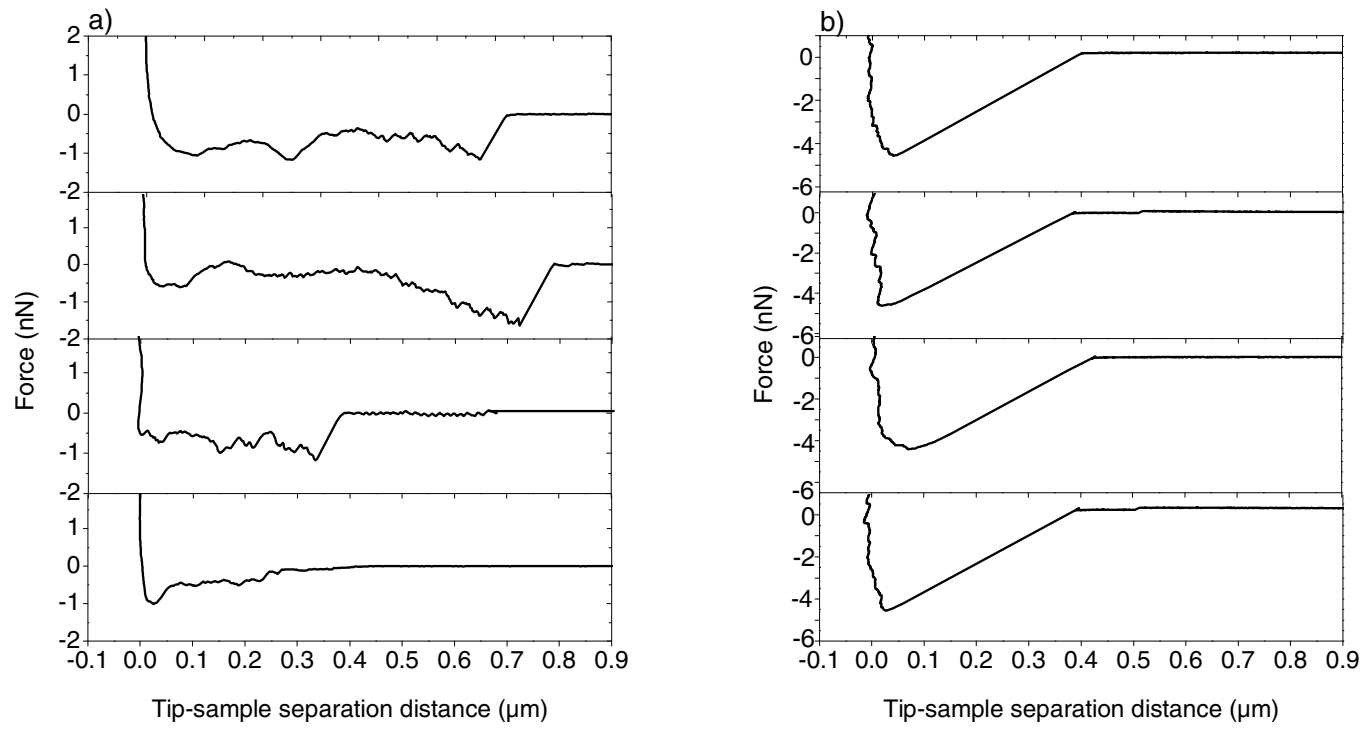

Figure S1. Representative AFM retraction curves taken on A. venetianus RAG-1 (a) and $R$. erythropolis 20S-E1-c (b) surfaces in phosphate buffer with the hydrophobic tip. The four force curves represent data obtained on different areas for the same bacterium. 


\section{Atomic Force Microscopy Measurement of Heterogeneity in Bacterial Surface Hydrophobicity (Supporting information)}
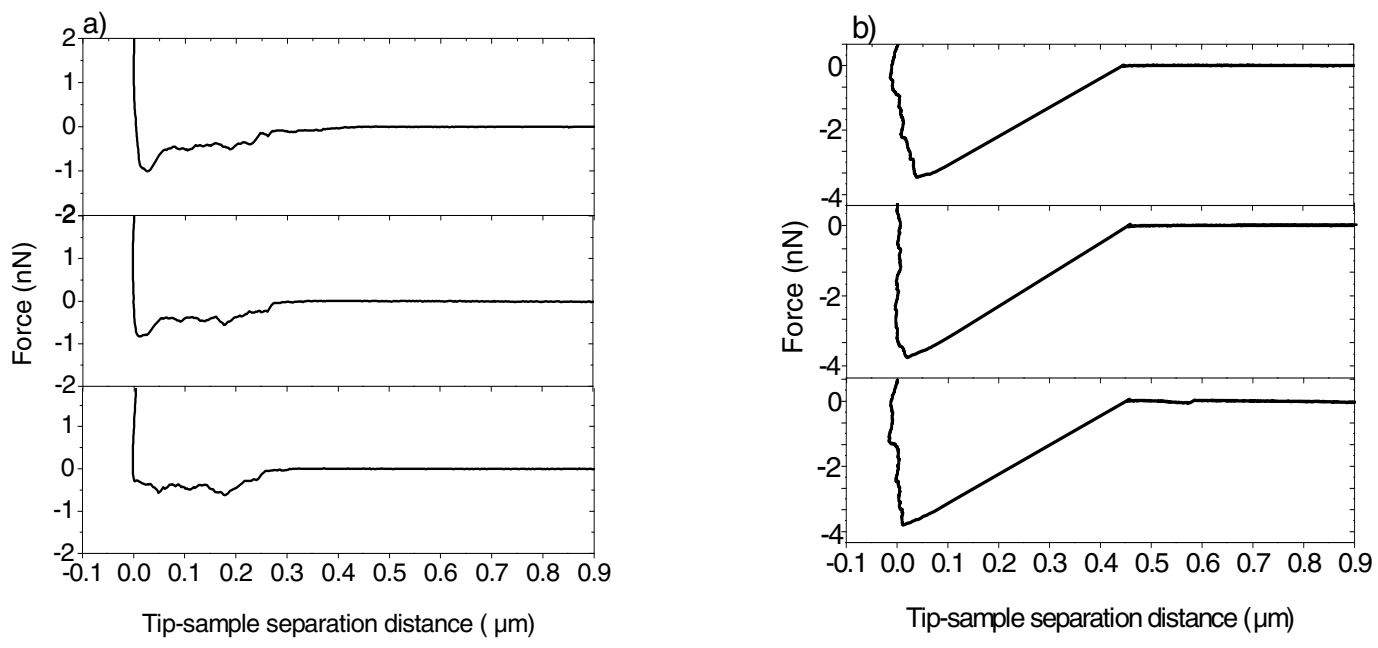

Figure S2. Representative AFM retraction curves taken on A. venetianus RAG-1 (a) and $R$. erythropolis 20S-E1-c (b) surfaces in phosphate buffer with the hydrophobic tip. The three force curves represent the repeatability of measurements at the same point on a bacterium surface. 


\section{Atomic Force Microscopy Measurement of Heterogeneity in Bacterial Surface Hydrophobicity (Supporting information)}
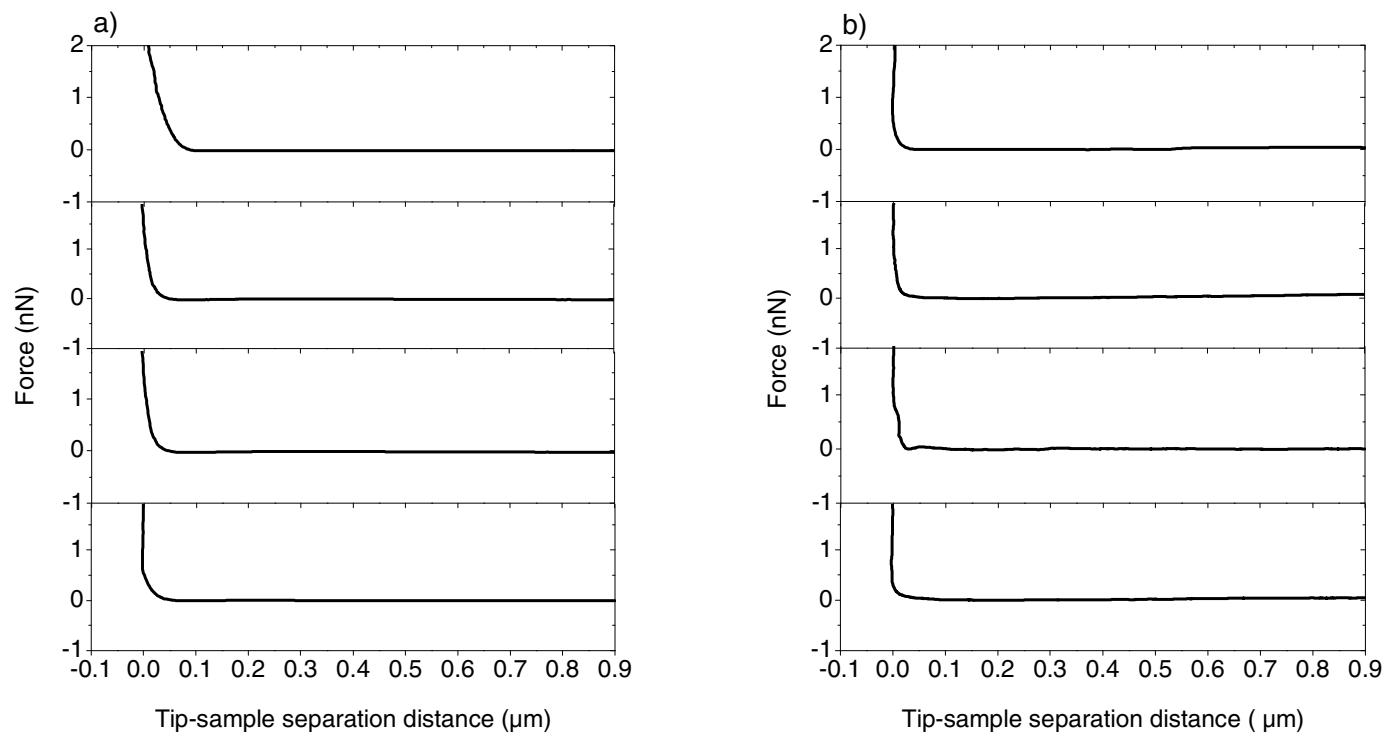

Figure S3. Representative AFM retraction curves taken on A. venetianus RAG-1 (a) and $R$. erythropolis 20S-E1-c (b) surfaces in phosphate buffer with the hydrophilic tip. The four force curves represent data obtained on different areas for the same bacterium. 